\title{
Os poemobjetos de Roberta Camila Salgado: criação e materialidade
}

Resumo: O artigo analisa a produção poética de Roberta Camila Salgado, que, entre 1964-1965, compôs os poemobjetos que viriam a integrar a instalação ambiental Tropicália, de Hélio Oiticica, exibida em 1967 na célebre exposição "Nova Objetividade Brasileira”. Relacionando a escrita poética com materiais como cerâmicas de telhado, blocos de tijolo, isopor e placas de madeira, a poeta torna tais materiais industrializados intrínsecos ao poema. O poemobjeto apresenta-se como uma conexão direta com o ambiente circundante; a poesia transforma-se em matéria aparentemente sem centralidade na atenção do leitor-participante, que passa a experienciá-lo como descoberta inesperada. Em suma, o presente artigo pretende examinar como a materialidade dos poemobjetos de Roberta Camila Salgado se situa dentro da esfera de produção poética brasileira.

Palavras-chave: poesia brasileira, Roberta Camila Salgado, Hélio Oiticica, poemobjetos

Abstract: This article aims to analyze the poetic production of Roberta Camila Salgado. Between 1964-1965 she created the poemobjetos [poemobjects], that would become part of Tropicália, an environmental installation created by Hélio Oiticica in 1967 and launched in the seminal exhibition "Nova Objetividade Brasileira". Camila Salgado's poetic writing uses materials such as roofing ceramics, brick blocks, Styrofoam and wooden boards. It appropriates the unusual aspect of those industrialized materials and makes them intrinsic to the poem. In this sense, the poemobjeto presents itself directly connected to the environment. Poetry becomes a sort of materiality that does not intend to control the attention of the observer/reader, who experiences it as an unexpected discovery. In short, this article intends to examine how Roberta Camila Salgado's poemobjetos and their materiality situate themselves within the Brazilian poetic milieu.

Keywords: Brazilian poetry, Roberta Camila Salgado, Hélio Oiticica, poemobjetos 
Nas linhas a seguir, iremos analisar a poesia de Roberta Camila Salgado (1936- ) e situá-la perante os demais processos de criação poética centrados nas relações com a materialidade. Para tanto, buscaremos remontar a relação de seus poemobjetos com a instalação ambiental Tropicália, de Hélio Oiticica, e o diálogo de ambas com o espaço do museu. Em seguida, buscaremos um recorte da concepção de poemobjeto, pleiteada por Roberta Camila Salgado, em contraste com um período recentemente anterior ao seu surgimento, isto é, com o das produções de poema-objetos das lavras concreta e neoconcreta. Por fim, faremos uma análise de questões formais e temáticas dos poemobjetos, a fim de atestar como a produção em questão aponta diretrizes singulares no tocante ao diálogo entre criação e materialidade.

Roberta Camila Salgado possui um processo criativo caracterizado por uma concisa e depurada produção poética. Apesar de ser uma poeta de longa data, Camila Salgado é, até o presente momento, pouco conhecida nos meios artístico e literário, recebendo somente em 2015 uma publicação que reuniria parcialmente sua obra poética (cf. Salgado 2015).

A poeta denomina grande parte de sua produção de poemobjeto, que, segundo ela, "[...] nada mais é que o poema em cima do objeto, que pode ser qualquer coisa [...]" (apud Mendonça 2017). Os poemobjetos são uma série de poemas geralmente concisos e curtos, elaborados após um largo período de tempo de experimentação e condensação da linguagem, e inscritos sobre materiais industrializados, de dimensões variadas e pertencentes ao espaço urbano, tais como cerâmicas de telhado, blocos de tijolo, peças de telhados de cerâmica, folhas de papelão, placas de isopor e de madeira. ${ }^{1}$ Os poemobjetos são inscritos manualmente e mediante o uso das cores preta, azul e vermelha. A maioria dos poemobjetos são pouco descritivos, algumas vezes compostos por uma pequena constelação de vocábulos que evocam imagens de reencontro com a natureza e ao mesmo tempo aludem a contextos sociopolíticos. A relação entre a palavra e o suporte não é, à primeira vista, evidente, o que permite acionar leituras diversas a respeito do encontro entre tais elementos.

Esta potencialidade da poesia de Roberta Camila Salgado despertaria a atenção do artista visual Hélio Oiticica, que selecionaria alguns de seus poemobjetos, compostos entre 1964 e 1965, para integrá-los à instalação ambiental Tropicália, exibida em 1967 na célebre exposição "Nova Objetividade Brasileira”, no Museu de Arte Moderna do Rio de Janeiro. A própria poeta declarara que "Hélio [Oiticica] gostava do que [ela] escrevia, principalmente da forma como apresentava [a] poesia: escrita sobre elementos os mais inusitados: telhas, tijolos, pedaços de madeira, zinco, plástico, tela, cerâmicas, isopor, etc. [...]" (Salgado 2015: 4).

De acordo com a publicação Tropicália: poemas 1965-1967 (Salgado 2015), seriam ao todo nove poemobjetos presentes na instalação ambiental de Hélio Oiticica, ${ }^{2}$ e que Roberta Camila Salgado chega a referi-los como tributos à Amazônia, poemas sobre a repressão política e poema dedicado aos arquitetos das favelas (Cf. idem: 23). Curiosa- 
mente, a inserção dos poemobjetos em Tropicália não contribuiu efetivamente para a visibilidade da poeta, muitas vezes sendo conferida ao Hélio Oiticica a autoria dos poemas. ${ }^{3}$ Ademais, a colaboração de Roberta Camila Salgado em Tropicália ainda carece da atenção de grande parte da crítica especializada, que geralmente opta por direcionar suas análises à instalação ambiental.

Remontando brevemente a genealogia da criação de Tropicália, é sabido que esta é um desdobramento de um projeto anterior e de maiores proporções, intitulado Projeto Cães de Caça, de 1961, elaborado no período neoconcreto de Oiticica, quem, por falta de financiamento, não pôde executá-lo em vida. O projeto pleiteava uma relação entre arquitetura e natureza ao propor um jardim de formato labiríntico e de escala pública para a vivência coletiva. Conforme as palavras de Hélio Oiticica,

esse projeto [Cães de Caça] seria algo como um jardim, aberto ao público, em uma cidade qualquer, de preferência num lugar amplo, como se fosse um parque, e não dando saída diretamente para ruas. A grande questão, porém, é a de que não se trata de um jardim habitual como se está acostumado a entender, com a utilidade pura e simples do jardim. Trata-se de um grande labirinto [...]. (Oiticica 2009a: 28-29)

Nesta espécie de jardim abstrato estariam incluídos o Teatro Integral, de Reynaldo Jardim, e o "Poema enterrado" (1959), de Ferreira Gullar, obras afinadas com os preceitos da poesia neoconcreta.

Como se pode atestar, Projeto Cães de Caça reservava em seu cerne um espaço para a intervenção poética, quando Hélio Oiticica sugerira os poetas neoconcretos supracitados como participantes - o que estava em consonância com a prática do grupo neoconcreto, onde artistas visuais e poetas desenvolviam diversos projetos em formato colaborativo. Já Tropicália apontava um caminho estético diverso ao do projeto precedente, inclusive na compreensão da natureza que, aqui, é transmutada em um jardim tropical composto por plantas, cascalhos e estruturas que remetem a um espaço urbano precário, mais precisamente à espacialidade das favelas cariocas de então. Contudo, Tropicália não aboliu a importância da poesia, prevista no projeto do qual ela se desdobrou. Inicialmente, Tropicália previa a inclusão de outros artistas:

[...] a necessidade de criar um ambiente tropical, do qual florescessem Penetráveis, também me veio como uma ideia de incluir nele obras de outros artistas: altar de [Rubens] Gerchman, caixas-viveiros de [Lygia] Pape, poemas-objeto de Roberta Oiticica [atual Roberta Camila Salgado], objetos lúdicos de [Pedro] Escosteguy. Mas, infelizmente, só foi possível realizá-la, incluindo os poemas-objeto de Roberta [...]. (Oiticica 2009b: 50)

O encontro profícuo entre Tropicália e a poesia de Camila Salgado é bastante exemplar da mudança de paradigmas pela qual a arte brasileira passava naquele período, 
quando artistas como Oiticica, egresso do movimento neoconcreto, veio a dedicar-se a novos estados inventivos de convivência entre arte e poesia experimental a partir da instauração de espaços comunais. A experiência poética de Roberta Camila Salgado, que inscrevia versos sobre materiais provenientes do espaço urbano - procedimento resultante do desejo de transpor os meios convencionais de inscrição e recepção da poesia -, estava em perfeita consonância com o caráter experimental de Tropicália. Os poemobjetos configuram-se como uma intervenção poética fundamental para potencialização da instalação ambiental de Oiticica, que compartilhava do mesmo desejo de engendrar um diálogo entre palavra e materiais pertencentes à esfera urbana brasileira.

I.

Segundo Roberta Camila Salgado, em retrospecto, o poemobjeto "[e]ra um projeto que [ela] pretendia desenvolver nas paradas de ônibus, restaurantes, aeroportos [...]" (apud Mendonça 2017). A declaração demarca o interesse da poeta pela realidade imediata, buscando ativar nos materiais industriais do cotidiano uma vibração poética. Contudo, devido à sua presença em Tropicália, os poemobjetos acabaram consequentemente inseridos em uma esfera para além do campo estritamente literário, isto é, no contexto dos museus. A relação entre a poesia e o espaço do museu já vinha sendo explorada pelos poetas concretos nos anos 1950, por exemplo. Neste sentido, é importante discorrer brevemente sobre como se dava a relação entre o espaço do museu e a produção de obras de arte na segunda metade do século XX, mais precisamente durante os anos 1960 e 1970.

Levando em consideração o panorama artístico brasileiro do período, é evidente a opção das novas vanguardas por um posicionamento dentro do museu, encarando-o como "espaço de negociação e enfrentamento artístico e cultural" (Baibich 2011: 52). Conforme apontado por Gonzalo Aguilar (2005: 55), isso se deve também a um aspecto modernizador historicamente atrelado ao museu em uma sociedade periférica, proporcionando novos espaços institucionais de exposição, novas situações para as vanguardas surgidas em uma época de reprodução (técnica). Conjugada com a problemática do museu como espaço de consolidação de certas manifestações artísticas e de produção de conhecimento na periferia geopolítica do mundo, a instalação ambiental de Hélio Oiticica, assim como a produção de Roberta Camila Salgado e de muitos poetas brasileiros daquele período, e salvaguardando suas especificidades estéticas, apostavam na materialidade da arte. Esta seria uma afirmativa da arte visual e/ou poética como "matéria vibrante" - para ficarmos com um termo de Jane Bennett (2010) - e por meio da qual se evidencia um "jogo de forças" vitais, heterogêneas e ao mesmo tempo compostas por intensidades diversas (cf. Bennet 2010: 54-57). Ao visibilizar a política material que constitui o contexto local, um segmento da arte brasileira de vanguarda opunha-se, em certa medida, à ideia da obsolescência do objeto em arte, então difundida pela produção artística internacional, especialmente o minimalismo estadunidense, que permitiu à crítica de arte Lucy Lippard, naqueles anos finais da 
década de 1960, constatar um processo de desmaterialização do objeto de arte visual (Lippard 1971: 255; Erber 2012).

Já na experiência sensório-visual proposta pela instalação de Hélio Oiticica e pelos poemobjetos de Roberta Camila Salgado encontramos um processo inverso, pois suas obras concentram-se na visibilização poética da matéria e da palavra, tratando-as como elementos potentes dentro de um contexto artístico-cultural periférico. Em Tropicália, Hélio Oiticica lança mão de panos de chita, areia, placas de compensado coloridas, plástico e telas de arame para a criação dos Penetráveis e de um viveiro para aves; nos poemobjetos, Camila Salgado utiliza blocos de tijolo, placas de isopor e peças de telha para a inscrição dos versos. Ambos os artistas trazem para o museu materiais considerados nada nobres e postos sobre uma organização espacial que remete diretamente a espaços desprivilegiados da realidade sociocultural brasileira, como favelas, terrenos baldios ou abandonados. No campo estético, ambas as produções dão um passo mais além da importante contribuição dos poetas neoconcretos ao se desviarem, em certo sentido, da defesa estrita de uma arte que privilegiasse o conhecimento fenomenológico e propusesse uma "síntese de experiências sensoriais e mentais" (Gullar 1959: s.p.), por sua vez fruto de uma ideia de percepção que não deixaria rastros. Se, por um lado, Oiticica e Camila Salgado apostavam em uma experiência artística que ainda flertava, em certa medida, com o preceito fenomenológico, por outro, a materialidade evocada em suas obras era bastante notável para operar como pura aparência, especialmente por relacioná-las com a realidade imediata, ao lançarem mão de materiais industrializados, advindos do cotidiano urbano brasileiro, porém apartando-os de sua condição serial. No caso dos poemobjetos, o uso de tais materiais advêm do desejo de tornar a poesia "presente em qualquer lugar dentro ou fora de casa, na parede ou no chão, nas ruas, nas esquinas, nas 'quebradas'”, conforme relatado pela poeta (Salgado 2015: 4). Portanto, o uso dos materiais industrializados resulta da aposta na potencialização da exterioridade da produção poética, que poderia localizar-se para além dos suportes convencionais como o livro, por exemplo, e ganhar a rua como espaço principal de circulação - embora este projeto, segundo a própria Roberta Camila Salgado, não tenha acabado dando certo (cf. Mendonça 2017). No entanto, ao instalarem-se dentro das quatro paredes do Museu de Arte Moderna do Rio de Janeiro, os poemobjetos, junto com Tropicália, materializam e inserem dentro da instituição uma espacialidade menosprezada, constituída por realidades sociais e substratos culturais situados fora do escopo da narrativa oficial do país. Uma espacialidade, por conseguinte, também portadora de uma experiência diversa e contrária às ideias de recepção e de contato convencionais projetadas sobre a obra de arte quando instaurada em um espaço expositivo.

Na realidade, os poemobjetos e Tropicália estão em diálogo direto com as premissas levantadas pela Nova Objetividade no final da década de 1960, e que, se em parte legatária do neoconcretismo, se particularizaria, por outro lado, ao voltar-se para a criação a partir de materiais já postos em circulação no espaço urbano, assim como ao dar maior atenção crítica aos contextos sociopolítico e cultural, sendo ambos os aspectos decorrentes de um 
exercício de "introdução dialética realista" e de intensificação da busca pela "aproximação participante" (Oiticica 2007: 225). Neste sentido, as obras de Camila Salgado e Oiticica seriam propostas artísticas afinadas com o que este último proferiu como uma "volta ao mundo', ou seja, um ressurgimento de um interesse pelas coisas, pelo ambiente, pelos problemas humanos, pela vida, em última análise" (idem: 229). ${ }^{4}$ O espaço do museu seria, portanto, elencado por aquelas obras que buscavam visibilizar tal retorno à experiência do cotidiano periférico ao lançarem mão de uma política material que ressaltava traços da realidade local, situada à margem da geopolítica mundial.

Conforme visto, os poemobjetos e Tropicália ainda se mantinham atrelados ao ambiente expositivo e não estavam instalados no espaço público e ao ar livre. Por outro lado, ao trazerem a presença do material urbano para o espaço do museu, tais obras fizeram o cotidiano (e ressaltemos mais uma vez: a realidade periférica) adentrar-se dentro da instituição a partir de sua materialidade precária.

II.

Através dos poemobjetos, Roberta Camila Salgado demarca a peculiaridade de sua prática perante atribuições convencionalmente conferidas às relações entre poesia e material, que, em outros períodos da produção poética brasileira, como os da lavra concreta e neoconcreta, foram cunhadas de forma bastante distinta.

No caso do poema-objeto dos concretos, seguindo aqui a esteira analítica de Nelson Baibich (2011: 64), é possível afirmar que tal produção é resultante de uma profunda discussão ético-política sobre a polifuncionalidade, atribuída à poesia. Era o momento que o poeta buscava um lugar para si em um contexto social ditado pelo design - ou pelo "esquema do 'design superior'”, como argumenta o crítico de arte Ronaldo Brito (1999: 76). No gesto dos concretos, reside uma recusa à permanência do lugar tradicional do poeta e de sua manufatura poética, especialmente a partir do questionamento radical do verso como unidade rítmico-formal (Baibich 2011: 65). Em relação ao âmbito estético-formal, conforme ressalta Alfredo Bosi (1994: 476), a produção concreta investe no processo de exploração das camadas materiais do significante, a ponto de rejeitar o esgotamento da obra a nível temático ou no campo da recepção. A versão tipográfica ou tecnicamente reprodutora da poesia, efetuada pelo processo convencional de sua impressão em formato livro, é abolida em prol de uma visão do poema como um objeto ocupando o espaço, como elemento central de uma série de relações estruturais (Baibich 2011: 62). Os poetas concretos primavam pela defesa da potência da escrita como uma comunicação não-verbal, direcionando-se, por conseguinte, a experimentações com as formas espaciais e a intervenção gráfica. Havia também a busca por uma extrema redução gramatical, fundada sobre uma interpretação bastante peculiar da escritura sino-japonesa e sobre as possibilidades entrevistas no ideograma. ${ }^{5}$

Em relação aos poemobjetos de Roberta Camila Salgado, há aspectos peculiares que precisam ser ressaltados quando postos em contraste com o poema-objeto concreto. Os 
poemobjetos, por exemplo, não resultam de uma visão da palavra e da matéria como partes integrantes de uma unidade indissolúvel, tal como defendida pelos concretos. Roberta Camila Salgado estaria mais interessada pelo encontro entre estes dois elementos, mas a ponto de que ambos ainda mantivessem as suas especificidades. A poeta ademais não rechaça o uso de referências da realidade externa, ou seja, os poemobjetos desviam-se da ideia de poesia como uma matéria inclinada ao registro autorreferencial aos campos da literatura e da arte. Os poemobjetos constantemente tomam a realidade como referente poético. 0 emprego das palavras como objetos autônomos - aspecto este que, segundo Pedro Erber (2012: 84-85), está bastante presente na produção poética concreta - não se efetua na poesia de Roberta Camila Salgado.

À primeira vista, é possível considerar os poemobjetos mais afinados com a produção poética neoconcreta, centrada na experimentação vivencial como posicionamento ético para além de um pensamento mecanicista e tecnicista da arte, caminhando na contramão do cientificismo e do racionalismo exacerbado. Na produção dos neoconcretos é verificável a busca de possibilidades expressivas a partir de outras experiências que considerassem a arte como corpus anti-mecanicista. Seus poemas parecem afastar-se de qualquer intenção didática e sobretudo da "armadilha desenvolvimentista" (Hollanda 2004: 46) presente no segmento das vanguardas poéticas, que acreditavam no subdesenvolvimento como etapa passível de superação, isto é, "[na] crença de que o país estaria ultrapassando o subdesenvolvimento, para ingressar numa nova era do país desenvolvido" (ibidem). Sob este prisma, pode-se dizer que a produção de Roberta Camila Salgado guardava, de forma indireta, uma afinidade ética com os neoconcretos, que se opunham às ideias de desenvolvimentismo presentes na vanguarda poética dos anos 1950 e que ainda produzia reverberações, embora já questionáveis, na década subsequente. Contudo, Roberta Camila Salgado vai mais além, ao proferir que "[o] poemobjeto, que é diferente do poema-objeto neoconcretista, é a tentativa de uma poesia sintética, que chegue ao âmago da ideia sem ser supérfluo" (apud Mendonça, 2017). Em que aspecto residiria então esta diferença, já que a síntese também é um aspecto presente na poesia neoconcreta?

A nosso ver, a diferença com o neoconcretismo é evidente quando refletimos sobre a relação entre palavra e material pleiteada por poetas como Ferreira Gullar. Em poema-objetos como "Lembra", de 1959, é perceptível uma vivência dialógica com a linguagem geométrica, lançando mão de superfícies quadriculares e planas ou de cubos que escondem e revelam a palavra; os livros-poema de Gullar, de folhas com recortes e tamanhos variados, permitem combinações das palavras ali dispostas através de seu manuseio. 0 primeiro poema supracitado e o próprio "Poema enterrado" são, conforme bem apontado por Fernando Gerheim (2020: 109), poesias visuais fundadas no emprego de um único verbo na forma imperativa ("lembra" e "rejuvenesça", respectivamente) e como palavra disparadora da sensação do leitor, que então é deslocado de uma leitura passiva para uma atitude mais participante diante das premissas apresentadas pelo poema. 0 jogo poético neoconcreto ainda flertava com a geometrização também presente no concretismo, 
embora distanciando-se deste último ao deslocar a forma geométrica "da racionalidade para a imaginação" (idem: 112).

Os poemobjetos de Roberta Camila Salgado, pelo menos os que compõem o ambiente da Tropicália, apontam para um caminho diverso. Se, por um lado, os poemobjetos guardam afinidades com o neoconcretismo na forma de lidar eticamente com a criação artística, por outro, se distanciam deste em relação ao entendimento dos encontros entre palavra e material, promovendo-os fora do jogo estritamente geométrico. Os poemobjetos resultam de um encontro entre a escrita e uma materialidade predominantemente atrelada ao cotidiano urbano, ao qual a sua poesia pretende se endereçar. Ao mesmo tempo, é possível inferir que os materiais usados como suporte também são partes constitutivas do espaço urbano e ao qual a poeta busca conferir uma potência poética. Os materiais utilizados não são, ademais, uma "criação", algo forjado pela poeta, porém matérias reaproveitadas, deslocadas de seu uso inicial e que não passam por nenhum processo de ajuste formal. Logo, os poemobjetos diferem-se de obras neoconcretas como "Onde", "Não", "Quando", "Lembra", "Era” e "Noite”, de Ferreira Gullar (1959) e "Livro da Criação" (1959), de Lygia Pape, que promovem uma relação entre material e palavra que, no entanto, guarda um espécie de geometrização do espaço, uma organização cromática e vocabular (mais precisamente no caso de Gullar) que ainda retém uma busca pelo equilíbrio espacial e uma preocupação pela estética das formas. Já os poemobjetos de Camila Salgado são uma materialidade artística precária e resultante de uma relação entre palavra (os versos) e material (os objetos industriais sobre os quais os versos são inscritos) interessada pela exterioridade da rua e por referenciar, através da linguagem e sem apelo a formalizações geométricas, a temas de seu tempo, como a opressão e o desmantelamento crescente do espaço público, em decorrência da ditadura que havia se instaurado no Brasil em 1964. Os poemobjetos de Camila Salgado são, portanto, uma busca pelo agenciamento com as forças do coletivo através desta aproximação entre palavra e material.

No tocante à palavra, os poemobjetos, ao mesmo tempo que não primam pela profusão combinatória de vocábulos, o seu jogo de coesão vocabular não chega a uma redução do número de significantes a ponto de flertar com o monossilabismo. Os poemobjetos desviam-se ademais do emprego verbal na forma imperativa e como palavra única de um poema. Neste sentido, os poemobjetos optam por um jogo mais propositivo e menos exigente de um gesto eficaz por parte do leitor-participante, evitando direcioná-lo a tal intento. Dito isso, pode-se afirmar que, nos poemobjetos, há menos interesse pelo controle, seja no âmbito da leitura ou da participação. ${ }^{6}$

Além de definir sua poesia como poemobjetos, Roberta Camila Salgado confere-lhe outra camada de leitura ao denominá-los como "haicai caboclo" (ibidem), justamente por centrar-se sobre uma poética (politicamente) amazonense, trazendo elementos relacionados ao ambiente da mata, ao mesmo tempo que evoca as materialidades advindas do espaço urbano. Esta denominação assinala uma voz poética que busca outras possibilidades de leitura e de experiência do entorno, e que não se restringe ao contexto citadino. 
A criação do haicai tal como experienciada por Roberta Camila Salgado, que aclimata o processo poético de matriz japonesa de acordo com as possibilidades locais, não é um procedimento isolado se levarmos em consideração o número de poetas brasileiros que vieram a praticá-lo a partir do século XX. ${ }^{7}$ Contudo, o próprio termo "haicai caboclo" contribui para demarcar a particularidade da criação de Camila Salgado, já que o mesmo se compõe da aglutinação do nome de um procedimento poético com uma nomenclatura racial de larga história no debate identitário brasileiro. Portanto, qual diferencial estaria sendo demarcado por meio daquele termo?

Tradicionalmente, o haicai é uma forma rápida, concisa e objetiva de composição poética formada por três versos de dezessete sílabas, sendo o primeiro e o terceiro versos compostos por cinco sílabas (redondilha menor) e o segundo com sete sílabas (redondilha maior). O experimento rítmico dos versos não seria a tônica do haicai tradicional, onde ademais é sempre demarcado o kigo, uma palavra que remete à estação do ano em que o poema foi criado. No entendimento de Haroldo de Campos, o haicai é uma produção poética cujo campo lexical é dotado da "mais arrojada modernidade" (Campos 1977: 58), além de ser originário de um idioma "aglutinante", que permite o surgimento de "palavras-montagem" devido à sua extrema maleabilidade para o procedimento compositivo (ibidem), entrevisto na elaboração dos ideogramas como ideias visuais. Já na acepção de Roland Barthes, fundamentada numa abordagem cultural, "[...] o haicai parece dar ao Ocidente direitos que sua literatura lhe recusa [...]" (Barthes 2007: 91). O haicai permite "encerr[ar] o que você vê, o que sente, num escasso horizonte de palavras [...]; com pouca despesa, sua escrita será plena" (idem: 92; grifo de Barthes).

Mediante tais pareceres, indagamos onde se encontra o traço do "método ideogramático" na poesia de Roberta Camila Salgado e se nesta também existe, em certo sentido, tal "economia da plenitude". Contudo, antes de avançarmos com tal indagação, é importante assinalar que o "haicai caboclo" não segue o padrão de metrificação e número de versos do haicai tradicional, e tampouco emprega a "palavra de estação" (kigo) em seus versos, preferindo, no entanto, assinalar aspectos da natureza que remetem ao entorno amazonense. Porém, isso não significa que a produção poética de Roberta Camila Salgado não esteja afinada com aspectos do procedimento poético do haicai, como, por exemplo, a extrema redução gramatical. Ao denominar seus poemas como "haicai caboclo", Roberta Camila Salgado parece sugerir uma terceira via para o entendimento tanto do haicai quanto de um fazer poético fundado no uso da coesão como método. Não se trataria aqui da plenitude barthesiana sobre o haicai e tampouco do investimento na busca por "palavras-montagem", mas de uma produção a partir de "montagem de mesclas" tal como a licença poética no uso do termo caboclo parece sugerir. ${ }^{8} \mathrm{O}$ termo evoca o imaginário da mata atrelada à região norte do Brasil, assim como a entidade cabocla da umbanda, vista como um comportamento mais próximo ao do humano e capaz de adentrar-se em regiões sombrias nem sempre visitadas pelos orixás e santos (cf. Boyer, 1999: 34). Na realidade, a entidade cabocla seria aquela que integraria as matrizes religiosas tanto europeias (os 
santos católicos) quanto negras (os orixás) através da representação do indígena e seus deuses (ibidem).

O poema de Roberta Camila Salgado que citamos a seguir é notório por elucidar como o imaginário da mata - ou uma certa filosofia "cabocla" - se adentra na tessitura de sua produção, atestando a própria denominação "haicai caboclo" conferida pela poeta:

\author{
sozinho \\ na mata ele vive \\ sozinho \\ na mata ele mora \\ da mata ele come \\ da mata ele vive \\ sozinho \\ na mata ele ama \\ na mata \\ da mata ele morre \\ sozinho \\ é mato \\ é mata
}

ELE VIVE

(Salgado 2015: 12)

Inscrito sobre uma placa branca de compensado, o poema opera como um cântico de resistência, remetendo às evocações dos cultos de umbanda à entidade cabocla, ou então a um sujeito em uma persistente vida amalgamada com a natureza, atrelado a uma experiência cíclica e indissociável do imaginário florestal. Neste sentido, ao mencionar a sua poesia como "haicai caboclo", Roberta Camila Salgado desvela a busca por um procedimento poético agregador dos substratos culturais afinados com a filosofia da mata. No termo "haicai caboclo" reside, sobretudo, uma insistência poética, ao mesmo tempo política e vivencial, como a seguinte declaração da poeta ressalta, a saber: "A maior parte da minha poesia celebra minhas origens, minha vida, minha convivência com a natureza, a alegria de pertencer a esse universo amazônico. Há também a vontade de eternizar 
personagens das matas, dos rios, das cidades, antes que desapareçam [...]. Espero que meus personagens sobrevivam..." (idem: 70$).{ }^{9}$

III.

Partindo para uma análise formal e temática dos poemobjetos, comecemos com a leitura daquele que consideramos emblemático devido à afinidade explícita com a proposta da Tropicália. Inscrito sobre uma placa de latão, o poema sugere uma lista descritiva de materiais que, ao fim, parecem condensar-se na menção à construção. O poema está dividido em três agrupamentos compostos por três elementos cada e que operam como núcleos combinatórios e dotados de um ritmo ternário:

CAIXA
ZINCO
PAPELÃO
AREIA
TERRA
CIMENTO
MADEIRA
LATÃO
ÁGUA
CONSTRUÇÃO
(idem: 13 )

De acordo com Roberta Camila Salgado, o poema acima é dedicado aos "'grandes' arquitetos das favelas e demais periferias" do Brasil (idem: 23). Esta dedicatória reitera o compartilhamento dos mesmos diálogos material e simbólico propostos por Tropicália, que aponta realidades socioculturais recorrentemente invisibilizadas. O poema inclusive contribui para potencialização da materialidade constitutiva de Tropicália, dando visibilidade, no campo verbal e de forma condensada, aos materiais que compõem o jardim tropical de Oiticica. O poemobjeto e Tropicália irmanam-se e se retroalimentam, pois ambos evocam materiais constitutivos da moradia das favelas, por sua vez considerada uma arquitetura precária, moldável e efêmera por combinar materiais perecíveis (papelão) com aqueles relacionados a construções de alvenaria (areia, terra, cimento). Com isso, é possível afirmar que o poemobjeto em questão é uma espécie de "poema do anti-concreto", que proporciona uma experiência fenomenológica oriunda de uma aparente objetividade inscrita na listagem de elementos pertencentes ao cotidiano urbano. Avançando um pouco mais na reflexão, pode-se, por outro lado, pensar o referido poema como legatário, porém 
crítico, de uma "leitura construtiva do real" (Brito 1999: 84) que vinha perpassando a produção artística brasileira daquelas décadas, que variava entre a afirmativa do projeto construtivo por meio de uma dinâmica progressista - aspecto que se desprendia das intervenções dos concretos no campo cultural - e a contestação de sua efetividade no contexto brasileiro - ou seja, o reconhecimento de sua crise, pleiteado por produções neoconcretas que assinalavam a impossibilidade de levar tal projeto adiante. Contudo, e para além de uma delimitação estrita da espacialidade que o conjunto de vocábulos possa sugerir - é ademais limitador nomear tais vocábulos como "versos" mediante à materialidade direta a qual eles evocam -, o poema promove um agrupamento em aberto de elementos materiais, interdependentes e ao mesmo tempo singulares, incitando a participação ativa do leitor para a sua elaboração. A “construção", portanto, está ainda à espera do "leitor em potencial”, ou seja, de uma figura participante que realize a mescla, combinatória e pessoal, dos vocábulos que alicerçam o referido poema.

Outra contribuição dos poemobjetos de Camila Salgado à Tropicália é a referência que alguns daqueles fazem à sombra de uma violência histórica que recai sobre a espacialidade brasileira. Assim, os poemobjetos inserem a instalação de Oiticica dentro de um recorte crítico que assinala uma espécie de vivência paradigmática da espacialidade tropical, onde convivem constantemente as experiências com a natureza e as do medo impostas pelo autoritarismo:

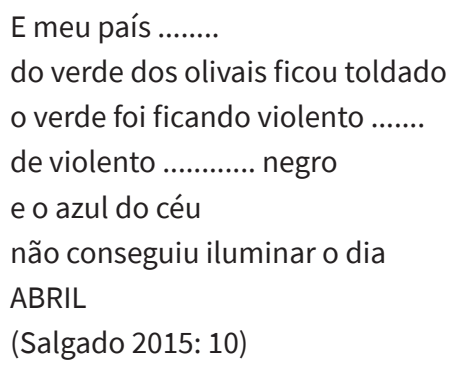

O poema acima, inscrito sobre uma placa de compensado, refere-se explicitamente ao contexto nacional, evidente na menção ao mês do golpe civil-militar no Brasil em 1964 . Ali são evocadas as cores que remetem aos emblemas nacionais, como o azul e o verde. Estas mantêm-se polarizadas entre o espaço nacional e o contexto político: o azul celeste é relacionado à espacialidade nacional, enquanto o verde, intensificado pela tonalidade oliva até atingir a tonalidade negra, opera como índice de uma violência iminente, além de remeter à cor verde oliva do uniforme militar brasileiro, consequentemente assinalando, de modo enviesado, a oficialização do autoritarismo recém-instaurado no país. 0 dia trevoso, toldando o espaço circundante, contrapõe-se à luminosidade celeste. Neste caso, há uma sugestão da ambiência dos regimes ditatoriais em contexto tropical, legível pela tensão entre a exuberância de um espaço natural e a incapacidade de transformar ou 
de transpor o poder de uma política ditatorial. A espacialidade natural é evocada como interlocutora e ao mesmo tempo como alvo de pedidos de mudança do contexto circundante que não parece se alterar:

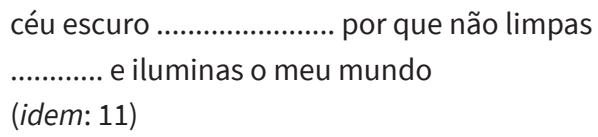

Estes exemplos relevam um aspecto importante da criação de Roberta Camila Salgado, ou seja, o jogo poético com uma paleta cromática composta por cores primária e secundária, situada entre o azul, vermelho e verde, além da cor preta, cinza e ocre. As cores operam às vezes como adjetivos, em outros momentos como substantivos compostos:

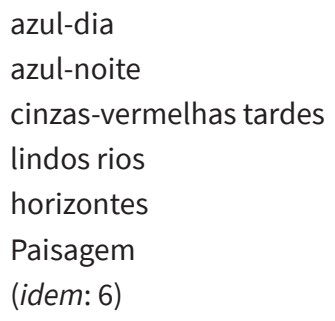

Em certo sentido, podemos inferir que o cromatismo evocado sustenta um diálogo íntimo dos poemas com a instalação ambiental de Hélio Oiticica, mesmo que esta se caracterize pelo uso de cores vibrantes. Há uma espécie de vibração cromática que extrapola o espaço da poesia, ao mesmo tempo que reitera o desejo de mudança aspirado pelo eu-lírico implícito em poemas como este, a saber:

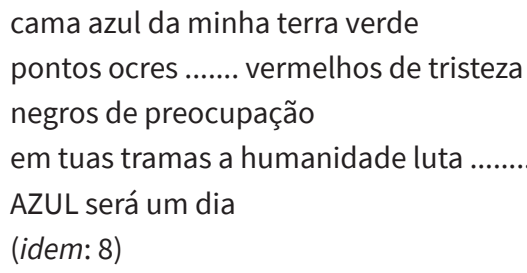

Aqui a cor inscreve-se não somente como temática, mas também na escolha da tinta empregada para a escrita dos versos, estando o último grafado em azul, enquanto os demais se mantêm em vermelho. A tonalidade azul ecoa sua carga cultural como cor associada tanto a uma liberdade revolucionária por vir quanto à violência. Em suma, as cores tornam-se referências ao espaço natural, além de associadas a um certo "estado de espírito", a nosso ver, estreitamente relacionado à atmosfera sufocante de um entorno 
então dominado pela ditadura, como alguns poemas anteriormente citados também parecem evocar. Por meio do uso do jogo cromático como elemento poético, os poemas de Roberta Camila Salgado revelam-se impregnados de subjetividade ao mesmo tempo que se apresentam regidos por um feitura concisa e rigorosa.

Em relação ao aspecto formal, é digno de nota o uso recorrente das reticências, que sobressaltam um espaço temporal onde ocorrem mutações frequentes. As reticências são empregadas como inscrição gráfica de uma temporalidade eclipsada, ao mesmo tempo que assinalam a transformação silenciosa e constante dos elementos naturais. Em vez do emprego das potencialidades poéticas do espaço em branco do papel pleiteadas por Stéphane Mallarmé, cujos recursos de criação seriam postos em evidência no circuito poético brasileiro através de textos teórico-críticos produzidos pelos poetas concretos ao longo dos anos 1950 e 1970 (cf. Campos et alii 1991), nos deparamos, em Roberta Camila Salgado, com as reticências atuando como elementos insistentes no espaço do poema. Em alguns deles, inscrito sobre tijolos, as reticências são um recurso de referência implícita ao registro sonoro:

as cigarras dão os seus acordes sirenes de fábrica

(Salgado 2015: 7)

Contudo, se entendemos a ideia das reticências como um sinal que inscreve a oralidade no campo da escrita, é possível experienciá-las, no caso dos poemas de Camila Salgado, como manifestação do indizível, de um registro vocal suprimido mas que se estende temporalmente na tessitura dos versos. Pode-se inclusive considerar as reticências como um recurso poético que materializa um discurso suprimido e hesitante, uma fala que se silencia - ou quiçá silenciada, e verificável em versos anteriormente citados, tais como "e meu país ........ / do verde dos olivais ficou toldado / o verde foi ficando violento

/ de violento negro" (idem: 10) e "cama azul da minha terra verde / pontos ocres ....... vermelhos de tristeza" (idem: 8). Levando em conta o próprio comentário da poeta, que assinala tais versos pertencentes a poemas criados sob um clima de censura e repressão política (idem: 23 ), torna-se ainda mais evidente como a presença das reticências materializa poeticamente o (auto)silenciamento sofrido por sujeitos inseridos em momentos históricos dominados por regimes autoritários. Sob este prisma, esta série de poemobjetos opera como imagem inversa da Tropicália, instaurando, no campo da linguagem, o silenciamento forçado como uma vibração de fundo que perpassa o solar e vibrante jardim tropical de Hélio Oiticica.

Os jogos de mutação cromática e de passagem da luminosidade à ausência de luz - aspectos estes já abordados - contribuem para reiterar a importância das reticências para a demarcação de um entorno opressor. Mas como os contextos podem ser variáveis de acordo com o correr da história, as reticências podem aparecer como sinalizações de 
uma transitoriedade - aspecto este intrínseco ao haicai tradicional, que "revela o estado transitório das coisas e da natureza" (Rebechi Júnior 2019: 135). Por vezes, as reticências apontam um porvir, inscrevem no corpo poético o vislumbre de mudanças positivas no contexto vigente, como reiteram os últimos versos de um poema anteriormente analisado: "em tuas tramas a humanidade luta / AZUL será um dia" (idem: 8).

Outra camada de leitura das reticências é entrevê-las como sinal gráfico de uma passagem do tempo inenarrável no espaço poético, como evidencia o poema a seguir, inscrito sobre uma telha de cerâmica:

o verde da mangueira desce é a relva

(idem: 7)

As reticências fazem o leitor deparar-se com um registro de incompletude, elas não Ihe concede a visão total da imagem poética evocada, exigindo-lhe um estado inventivo perante os versos. Neste caso, as reticências desempenham o papel comunicacional da própria estrutura do poema, indo para além da comunicação de enunciados poéticos algo que, paradoxalmente, os poemobjetos de Roberta Camila Salgado não pretendem se desvencilhar plenamente, já que nem sempre a poeta abre mão do referencial sociocultural e da realidade imediata como elementos para a produção poética.

Outro aspecto importante a ser frisado, uma vez mais, é a relação da escrita com os materiais empregados. Roberta Camila Salgado não faz uso da folha de papel, mas, como vimos anteriormente, de materialidades atreladas ao universo da construção industrial e civil. Entretanto, a poeta não descarta a importância do suporte livro, como ela mesmo uma vez afirmara: "[m]inha proposta não elimina o livro de poesia, que deve existir. O que sugiro é que a poesia se faça presente no dia a dia das pessoas, das cidades, como acontece quando é musicada" (idem: 4). Por outro lado, no caso dos poemobjetos em Tropicália, inscritos em superfícies diversas, o suporte tradicional do livro é suprimido, não estando portanto o poema isolado do espaço circundante - uma supressão da "base" que não deixa de se relacionar com o modo neoconcreto de pensar produção artística e espaço de forma não-instrumental, e verificável, por exemplo, nos "bichos" de Lygia Clark (cf. Brito 1999: 80-81). Em Roberta Camila Salgado, a poesia é uma arte destituída do ato de folhear páginas, isto é, de uma experiência temporal, rítmica e propensa à sequencialidade. A poesia seria mais bem uma experiência inconstante, que se dá pela deambulação na instalação ambiental de Oiticica, podendo o leitor-participante porventura esbarrar, ou "tropeçar" com os poemobjetos.

Neste sentido, é preciso relembrar que a espacialidade de Tropicália é dotada de um caminho tortuoso feito de areia e pedra, e ao longo do qual os poemobjetos estão dispostos, com a maioria deles rente ao chão ou escorados sobre vasos de plantas. Portanto, e no âmbito da recepção artística, a deambulação apresenta-se como um movimento 
importante para o acontecimento poético. A poesia transforma-se em acontecimento no espaço, decorrente do ritmo errante do movimento deambulatório. A poesia, por conseguinte, dá-se como uma experiência do "tropeço", como uma condição física que interrompe a sequencialidade do tempo cotidiano. O poemobjeto torna-se matéria aparentemente sem centralidade na atenção do leitor-participante, que passa a experienciá-lo como descoberta inesperada. 0 tropeço apresenta-se como possibilidade de encontro (físico, perceptivo) do leitor-participante com o poemobjeto, que por sua vez não se pretende protagonista dentro da espacialidade da instalação. Logo, a experiência espaciotemporal proposta pelos poemobjetos de Roberta Camila Salgado está bastante afinada com a proposição de Hélio Oiticica. Neste aspecto, a produção de Camila Salgado também estaria irmanada com as premissas artísticas da exposição "Nova Objetividade Brasileira", que foi o evento de estreia tanto dos poemobjetos como de Tropicália e que teria como um de seus aspectos "a participação do leitor/espectador num tipo de escrita desdobrada no espaço, em que a palavra deve[ria] ser encontrada" (Gerheim 2020: 114). Dito de outra maneira, reside neste encontro inesperado com os poemobjetos, por meio de uma experiência deambulatória pela instalação ambiental, um gesto a contrapelo do mecanicismo, um gesto de recusa a uma participação mediada pela tecnologia. Neste sentido, o poemobjeto aproxima-se da política de outras produções dissidentes dos anos 1960 e 1970, centradas na conjugação entre certa precariedade material, ênfase na feitura artesanal e ativação de uma postura participadora. ${ }^{10} \mathrm{O}$ poemobjeto não estaria completamente estrito ao plano óptico ou de "leitura", mas na experimentação do encontro físico com aquele, por meio do "tropeço" do observador, agora tornado um caminhante participador, que esbarra com os poemobjetos pelas "quebradas" da Tropicália. Encontramos aqui, portanto, uma "experiência (poética) do tropeço", que se instaura pela disposição espacial dos poemobjetos nos meandros da instalação ambiental. A poesia efetiva-se como um encontro espaciotemporal e imprevisível, uma relação entre poemobjeto e leitor-participante fundada pelo encontro inesperado entre ambos.

Em relação ao modo de inscrição, os poemobjetos são escritos à mão, assinalando um aspecto artesanal na produção de Roberta Camila Salgado. Em vez do procedimento tipográfico, a poeta reproduz manualmente a tipografia industrial em certos poemobjetos, escritos em caixa alta. O uso da caligrafia é apartado do espaço técnico e, por isso, acentua a presença de uma experiência mais subjetivada, onde se entrevê um rastro físico da poeta, ou seja, a sua letra. Logo, o seu gesto de feitura e difusão poética distancia-se das possibilidades oferecidas pelas novas tecnologias então emergentes, e das quais a poesia concreta soube brilhantemente tirar proveito como suporte e linguagem, embora a produção dos concretos, a despeito de sua aparência industrial, também portasse traços artesanais. É possível que os poemobjetos de Roberta Camila Salgado estivessem apontando, a partir deste desvio da tecnicidade, a busca por uma diálogo mais contundente, e sem anteparos, com a realidade brasileira, e mais precisamente com a fatia mais desprivilegiada da sociedade. 
A título de conclusão, inferimos que a poesia de Roberta Camila Salgado promove um desvio no pensamento sobre o espaço de inserção, recepção e difusão do poema ao apropriar-se do aspecto inusitado de materiais industrializados e ao torná-los intrínsecos ao poema. O poemobjeto apresenta-se em conexão direta com o ambiente circundante, além de metamorfosear-se em matéria aparentemente sem centralidade na atenção do leitor-participante, passando a experienciá-lo como descoberta inesperada. Poemobjeto é um termo que reforça o espírito de encontro entre a materialidade da palavra e a concretude do material sobre o qual aquela é inscrita. Ademais, cabe ressaltar, a título de curiosidade, o insistente gesto da poeta de reinscrever os mesmos versos em outros materiais, buscando novas combinações possíveis. Isso evidencia o caráter continuamente experimental de Roberta Camila Salgado, o constante trabalhar sobre sua produção poética ao longo de décadas. ${ }^{11}$ Como apontado por Sergio Cohn (2015: 3-6) na apresentação do livro que reúne a produção poética de Camila Salgado, os poemobjetos possuem particularidades na linguagem e no suporte, por serem versos curtos e inscritos em "suportes inusitados e além-livro" (idem: 3-4). No entanto, conforme assinalado no início deste artigo, a contribuição da poeta esteve afinada com os preceitos estéticos de Tropicália a ponto de seus poemas ficarem eclipsados no meio do debate artístico-literário, comumente voltado à análise da instalação ambiental em questão. ${ }^{12}$ É fato que ambas as obras podem ser lidas como produções independentes. Contudo, existe uma escassez de estudos que abordem as peculiaridades da produção poética de Roberta Camila Salgado, e o presente artigo buscou contribuir, de forma modesta, para a redução desta lacuna, empreendendo uma análise dos poemobjetos e buscando uma abordagem de sua posição ímpar perante os entendimentos anteriores fomentados sobre a relação entre materialidade e verso.

\section{NOTAS}

* André Masseno é doutor em Letras Portuguesas pela Universidade de Zurique (UZH). Mestre e especialista em Literatura Brasileira pela Universidade de Estado do Rio de Janeiro (Uerj). Professor de Língua Portuguesa na Universidade de São Galo. Membro da equipe editorial da revista Língua-lugar: Literatura, História, Estudos Culturais (Universidade de Genebra-Universidade de Zurique) Organizador das publicações Antropofagias: um livro manifesto! Práticas da devoração a partir de Oswald de Andrade (com Pauline Bachmann et alii, Ed. Peter Lang, 2021), Bioescritas/Biopoéticas : pensamentos em trânsito (com Daniele Ribeiro Fortuna e Marcelo dos Santos, Ed. Pontocom, 2018), Bioescritas/Biopoéticas: corpo, memória, arquivos (com Ana Chiara et alii, 
Ed. Sulina, 2017), entre outros. Atualmente é pós-doutorando associado da UZH, onde desenvolve sua pesquisa sobre aspectos da materialidade da produção artístico-literária latino-americana dos anos 1960 e 1970.

${ }^{1}$ As descrições dos poemobjetos de Roberta Camila Salgado feitas ao longo do presente artigo são baseadas na reprodução fotográfica dos mesmos em Tropicália: poemas 1965-1967 (Salgado 2015). Contudo, é importante frisar que as reproduções não são definitivas, pois os materiais usados pela poeta como suporte sempre foram diversos ao longo do tempo, variando a cada montagem da instalação de Hélio Oiticica.

2 Já a página web do museu espanhol Reina Sofía, detentor de uma cópia de Tropicália, descreve o número de dez poemobjetos em seu acervo. Cf. <https://www.museoreinasofia.es/coleccion/obra/tropicalia-penetraveis-pn2-pureza-e-um-mito-pn3-imagetico-tropicalia-penetrables-pn2> (último acesso em 29/05/2021).

${ }^{3} \mathrm{~A}$ invisibilidade conferida à obra de Roberta Camila Salgado é exemplar na página web do museu britânico Tate Modern, que adquiriu em 2007 a versão original Tropicália em seu acervo e que descreve os poemobjetos como escritos de Hélio Oiticica. Cf. <https://www.tate.org.uk/art/artworks/oiticica-tropicalia-penetrables-pn-2-purity-is-a-myth-and-pn-3-imagetical-t12414> (último acesso em 29/05/2021).

${ }^{4}$ Em certa passagem do texto "Esquema geral da Nova Objetividade", publicado no catálogo da exposição "Nova Objetividade Brasileira", Hélio Oiticica menciona o seu interesse por uma criação que considere os objetos cotidianos como produto artístico: "[Waldemar] Cordeiro com o Popcreto prevê de certo modo o aparecimento do conceito de 'apropriação' que formularia eu dois anos depois (1966) ao me propor uma volta à 'coisa', ao objeto diário apropriado como obra" (Oiticica 2007: 224; grifos nossos).

${ }^{5} \mathrm{~A}$ leitura dos concretos sobre a escrita chinesa é fundamentada sobre os estudos de Ernest Fenollosa e Ezra Pound (1977), que, em linhas gerais, tomavam aquela como meio poético de revitalização da poesia ocidental.

${ }^{6} \mathrm{O}$ interesse pelo controle da leitura e da participação uma característica marcante nos livros-poema de Ferreira Gullar, conforme ressalta Teodoro Rennó Assunção: "A participação do leitor no manuseio das páginas obedece, portanto, a uma ordem tão esperada quanto a da numeração sequencial das páginas em um livro comum, e é menos livre [...], pois a intenção inicial de Gullar era justamente controlar, sem nenhuma margem de equívoco, este modo de leitura" (Assunção 2013: 158).

${ }^{7}$ Poetas como Afrânio Peixoto, Alice Ruiz, Guilherme de Almeida, Helena Kodoy, Luiz Bacellar, Millôr Fernandes, Paulo Leminski e Pedro Xisto praticaram o haicai ao longo de sua trajetória e de forma diversificada. Para maiores detalhes sobre a produção e a recepção do haicai no Brasil, cf. Franchetti 2012 e Goga 1988.

${ }^{8}$ Cabe lembrar a nomenclatura "caboclo", de fundo racial e biologista, fora forjada pelo Brasil colonial do século XIX para denominar, de forma maniqueísta, a população oriunda do suposto "encontro" (um eufemismo para a violência) entre as matrizes branco-europeia e a indígena; em outras palavras, caboclo seria um termo reducionista que guarda o complexo e tenso imaginário da "fusão" entre etnias e culturas, que, no entanto, oculta um pano de fundo historicamente colonial e discriminatório, marcado por intervenções extremamente violentas (cf. Castro 2013: 433).

${ }^{9}$ Interessante notar como a declaração de Roberta Camila Salgado é ambígua. Por um lado, ela ecoa, em certo sentido, o imaginário apocalíptico sobre o universo amazônico e que possui um vasto legado na produção poético-literária latino-americana; por outro, ela expressa uma esperança, uma leitura positivada de tal universo como gerador de resistências e modos de sobrevivência perante às adversidades. A respeito das leituras do espaço amazônico e de suas etnias como fadadas ao desaparecimento, e alimentadas por certas obras 
notáveis da literatura na América Latina, cf. Sá 2012: 365-379.

${ }^{10}$ Este caráter pode ser entrevisto em produções poéticas de características diversas, como a chamada "poesia marginal" (com o uso do mimeógrafo e da distribuição informal) e o poema/processo, mais especialmente a experiência interativa de "A corda" (1967), de Neide Dias de Sá, para ficarmos com alguns exemplos.

${ }^{11}$ Em uma conversa informal com o autor em 2019, o curador César Oiticica Filho comentou que, mesmo para as exibições atuais de Tropicália, Roberta Camila Salgado ainda experimenta novos materiais e combinações para os poemobjetos ali inseridos, o que revela um gesto constante de recriação daqueles por parte da poeta.

${ }^{12} \mathrm{~A}$ título de pesquisa futura, esperamos engendrar uma análise da circulação de Tropicália e dos poemobjetos posterior à exposição da Nova Objetividade Brasileira, a fim de verificar até que ponto os poemobjetos participaram ou não de exposições subsequentes e se, no histórico da aquisição patrimonial de Tropicália, aqueles configuram-se ou não como uma parte integrante.

\section{BIBLIOGRAFIA}

Aguilar, Gonzalo (2005), Poesia Concreta Brasileira. As vanguardas na encruzilhada modernista, São Paulo, Editora da Universidade de São Paulo.

Assunção, Teodoro Rennó (2013), “Os ‘livros-poema' e os 'poemas espaciais' de Ferreira Gullar e os Bichos de Lygia Clark”, O Eixo e a Roda, Belo Horizonte, v. 22, n. 2, 151-171.

Baibich, Nelson (2011), O Vai e Vem do Verso. As relações da poesia concreta com a publicidade impressa, Palhoça, Ed. Unisul.

Barthes, Roland (2007), O Rumor da Língua, tradução de Leyla Perrone-Moisés, São Paulo, Martins Fontes.

Bennet, Jane (2010), Vibrant Matter. A Political Ecology of Things, Durham e Londres, Duke University Press.

Bosi, Alfredo (1994), História Concisa da Literatura Brasileira, São Paulo, Cultrix.

Boyer, Veronique (1999), “O pajé e o caboclo: de homem à entidade”, Mana, vol. 5, n. 1, Rio de Janeiro, 29-56.

Brito, Ronaldo (1999), Neoconcretismo. Vértice e ruptura do projeto construtivo brasileiro, São Paulo, Cosac Naify.

Campos, Augusto de (1977), A arte no Horizonte do Provável, São Paulo, Perspectiva.

Campos, Augusto de/ Décio Pignatari/ Haroldo de Campos (1991), Mallarmé, São Paulo, Perspectiva. 
Castro, Fábio Fonseca de (2013), "A identidade denegada: discutindo as representações e a autorrepresentação dos caboclos na Amazônia", Revista de Antropologia, São Paulo, USP, vol. 56, n. 2, 431-475.

Cohn, Sergio (2015), “Apresentação”, in Salgado, Roberta Camila, Tropicália (1965-1967). Verdes correntes (1965-2015), Rio de Janeiro, Beco do Azougue, 3-6.

Erber, Pedro (2012), "The Word as Object: Concrete Poetry, Ideogram, and the Materialization of Language", Luso-Brazilian Review, vol. 49, n. 2, 72-101.

Fenollosa, Ernest/ Ezra Pound (1977), El carácter de la escritura china como medio poético, tradução espanhola de Mariano Antolín Rato, Madri, Visor.

Franchetti, Paulo (2012), Haicai. Antologia e história, Campinas, Editora da Unicamp.

Gerheim, Fernando (2020), "Cruzamentos entre palavra e imagem em três momentos da arte brasileira”, Ars, Rio de Janeiro, UFRJ, ano 18, n. 39, 105-128.

Goga, Masuda (1988), O Haicai no Brasil, São Paulo, Oriento.

Gullar, Ferreira (1959), “Teoria do não-objeto”, Jornal do Brasil, Suplemento Dominical, 19 e 20 de dezembro, Rio de Janeiro, s.p.

Hollanda, Heloísa Buarque de (2004), Impressões de Viagem. CPC, vanguarda e desbunde 1960/70. Rio de Janeiro, Aeroplano [1981].

Lippard, Lucy (1971), "The Dematerialization of Art”, in Changing. Essays in Art Criticism, Nova Iorque, E. P. Dutton \& Co., 255-76 [Art International, vol. XII, N. 2, 1968].

Mendonça, Rosiel (2017), "Autora dos poemas da obra 'Tropicália', de Hélio Oiticica, lança livro em Manaus”, Acrítica, <https://www.acritica.com/blogs/bem-viver-blog/posts/ autora-dos-poemas-da-obra-tropicalia-de-helio-oiticica-lanca-livro-em-manaus> (último acesso em 09/02/2021).

Oiticica, Hélio (2007), "Esquema geral da Nova Objetividade”, in Tropicália. Uma revolução na cultura brasileira, organização de Carlos Basualdo, São Paulo, Cosac Naify, 221-231.

-- (2009a), “Projeto Cães de Caça e pintura nuclear”, in Hélio Oiticica, organização de Cesar Oiticica Filho, Sergio Cohn e Ingrid Vieira, Rio de Janeiro, Beco do Azougue, 28-33.

-- (2009b), "Tropicálias e Parangolés", in Hélio Oiticica, organização de Cesar Oiticica Filho, Sergio Cohn e Ingrid Vieira, Rio de Janeiro, Beco do Azougue, 48-55.

Rebechi Júnior, Arlindo (2019), "Haikai, a poética da intensidade e da percepção", Comunicação \& Educação, São Paulo, USP, ano 24, n. 1, janeiro-junho, 128-140.

Sá, Lúcia (2012), Literatura da Floresta. Textos amazônicos e cultura latino-americana, Rio de Janeiro, EdUERJ.

Salgado, Roberta Camila (2015), Tropicália (1965-1967). Verdes correntes (1965-2015), Rio de Janeiro, Beco do Azougue. 